\title{
RNA target specificity of the embryonic cell fate determinant POS-1
}

\author{
BRIAN M. FARLEY, JOHN M. PAGANO, and SEAN P. RYDER \\ Department of Biochemistry and Molecular Pharmacology, University of Massachusetts Medical School, Worcester, Massachusetts 01605, USA
}

\begin{abstract}
Specification of Caenorhabditis elegans body axes and cell fates occurs prior to the activation of zygotic transcription. Several CCCH-type tandem zinc finger (TZF) proteins coordinate local activation of quiescent maternal mRNAs after fertilization, leading to asymmetric expression of factors required for patterning. The primary determinant of posterior fate is the TZF protein POS-1. Mutants of pos-1 are maternal effect lethal with a terminal phenotype that includes excess pharyngeal tissue and no endoderm or germline. Here, we delineate the consensus POS-1 recognition element (PRE) required for specific recognition of its target mRNAs. The PRE is necessary but not sufficient to pattern the expression of a reporter. The PRE is distinct from sequences recognized by related proteins from both mammals and nematodes, demonstrating that variants of this protein family can recognize divergent RNA sequences. The PRE is found within the $3^{\prime}$ untranslated region of 227 maternal transcripts required for early development, including genes involved in endoderm and germline specification. The results enable prediction of novel targets that explain the pleiotropy of the pos- 1 phenotype.
\end{abstract}

Keywords: post-transcriptional regulation; embryogenesis; tandem zinc finger; RNA binding; germline specification

\section{INTRODUCTION}

During the first few rounds of cell division in the development of a metazoan, body axes are formed, cell fates are specified, and a rough body plan is established. In many species, these events occur without the benefit of zygotic transcription, relying instead on the asymmetric localization and translation of specific maternally supplied mRNAs (for review, see Farley and Ryder 2008). A network of cis-acting regulatory elements and cognate trans-acting specificity factors, including RNA-binding proteins and microRNAs, is required to ensure that mRNAs are appropriately regulated. Frequently, the cis-acting regulatory elements are found in the $3^{\prime}$-untranslated region $\left(3^{\prime}\right.$ UTR) of mRNAs, as this region is not actively spliced or translated and is therefore readily accessible to the transacting regulatory factors (for review, see Kuersten and Goodwin 2003).

Early embryogenesis in the nematode Caenorhabditis elegans requires the regulation of an extensive network of

Reprint requests to: Sean P. Ryder, Department of Biochemistry and Molecular Pharmacology, University of Massachusetts Medical School, Worcester, MA 01605, USA; e-mail: sean.ryder@umassmed.edu; fax: (508) 856-6464.

Article published online ahead of print. Article and publication date are at http://www.rnajournal.org/cgi/doi/10.1261/rna.1256708. maternally supplied mRNAs, as the onset of zygotic transcription is delayed. Prior to the initiation of zygotic transcription, the fates of all of the founder cells that produce the tissues and organs present in the adult worm are established (Fig. 1; Sulston et al. 1983). This process begins soon after fertilization, when the zygote divides asymmetrically across the anterior-posterior axis. The larger anterior daughter is the first founder cell, while the smaller posterior daughter is the progenitor of the germline. The germline progenitor repeats this pattern of asymmetric cell division three more times, eventually giving rise to six total founder cells that together are the progenitors of all the tissue types present in the adult worm (Sulston et al. 1983). Most cells of the zygote do not begin transcription until the four-cell stage, and transcription does not begin in the germline lineage until just prior to gastrulation (Mello et al. 1996; Seydoux et al. 1996; Seydoux and Dunn 1997). Thus, post-transcriptional regulation of maternal transcripts by maternal RNA-binding proteins is the primary mechanism that drives cell fate specification in the early embryo.

POS-1 is a critical RNA-binding protein required for C. elegans early embryogenesis (Tabara et al. 1999; Ogura et al. 2003). POS-1 accumulates in the posterior of the fertilized zygote and is inherited asymmetrically at each division (Fig. 1). Embryos lacking POS-1 fail to hatch; the 
A

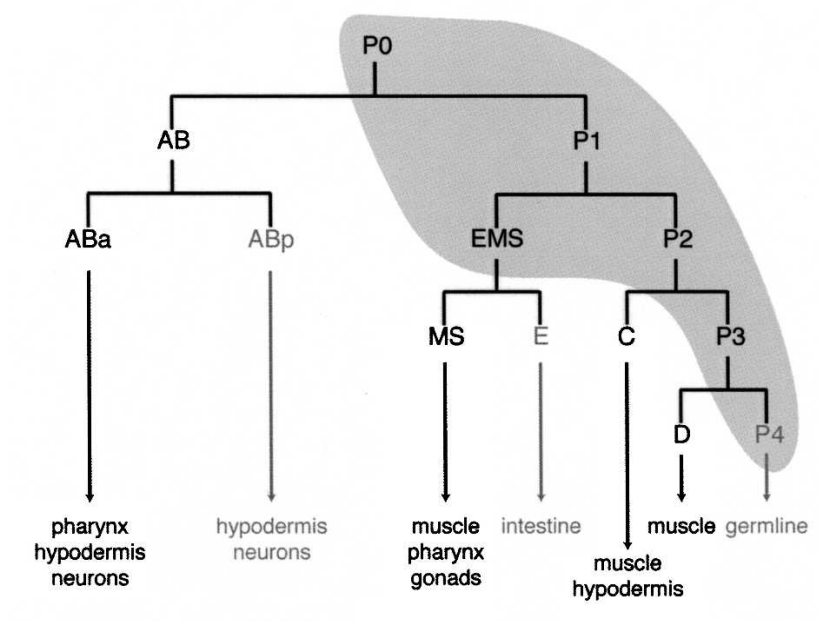

B

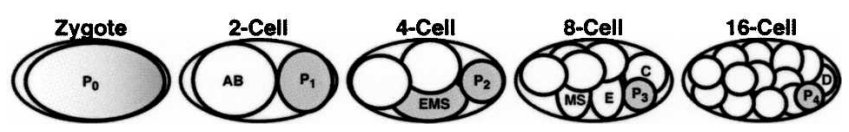

FIGURE 1. POS-1 is required for the specification of multiple cell fates in the early C. elegans embryo. (A) The early C. elegans cell lineage is shown, with each founder cell labeled with the tissue types it produces. The expression of POS-1 protein is shown in gray, and each founder cell specified incorrectly in pos-1 mutant embryos is grayed out. (B) Schematic of POS-1 expression in early embryos. POS-1 expression is shown in gray, and each founder cell is labeled.

terminally differentiated embryos lack intestine and germ cell precursors and have excess pharyngeal tissue. Each of these tissue types is derived from a different founder cell, indicating that POS-1 is required for multiple cell fate specification events. The pleiotropy of the pos-1 mutant phenotype suggests that it governs multiple aspects of maternal gene regulation.

Three genes have been identified whose expression is perturbed in pos-1 mutants: $g l p-1, a p x-1$ (Ogura et al. 2003), and nos-2 (D'Agostino et al. 2006). nos-2 encodes a protein similar to Drosophila Nanos that is required for germ cell development and migration during gastrulation (Subramaniam and Seydoux 1999). $g l p-1$ encodes a cell surface receptor homologous to Drosophila Notch, and apx-1 encodes a ligand homologous to Drosophila Delta that is recognized by GLP-1 (Fehon et al. 1990; for review, see Artavanis-Tsakonas et al. 1999). APX-1 and GLP-1 are required to pattern anterior development; their interaction at the two-cell stage polarizes the anterior blastomere as it divides, causing its posterior daughter $(\mathrm{ABp})$ to adopt a hypodermal fate (Mello et al. 1994). In pos-1 mutants, GLP-1 is aberrantly expressed in all cells of the early embryo, while APX-1 expression is undetectable (Ogura et al. 2003). This prevents polarization of the two-cell stage anterior blastomere, causing the formation of excess pharyngeal tissue at the expense of hypodermis.
The mRNA encoding $g l p-1$ is present in every cell of the embryo until the eight-cell stage, but GLP-1 protein is expressed only in the anterior of the embryo (Evans et al. 1994; Ogura et al. 2003). The $g l p-13^{\prime}$-UTR is both necessary and sufficient to direct this expression pattern, as microinjected mRNA encoding a lacZ reporter under control of the $g l p-13^{\prime}$-UTR is expressed in a pattern identical to endogenous $g l p-1$ (Evans et al. 1994). This suggests that $g l p-1$ mRNA is translationally repressed through its $3^{\prime}$-UTR in the posterior of the embryo. Two 70-nucleotide (nt) elements within the $3^{\prime}$-UTR, termed the spatial control region (SCR) and the temporal control region (TCR), are required for both spatial and temporal patterning. Within the SCR are two regulatory subelements required for translational repression ( $g l p-1$ repression element [GRE]) and translational activation ( $g l p-1$ derepression element [GDE]) (Marin and Evans 2003). The STAR-domain RNA-binding protein GLD-1 binds directly to the GRE, but the trans-acting factor that mediates regulation of $g l p-1$ through the GDE is not known (Lee and Schedl 2001, Marin and Evans 2003, Ryder et al. 2004). By yeast-three hybrid, POS-1 associates with both the SCR and TCR, suggesting that it represses translation of $g l p-1$ through direct association (Ogura et al. 2003). However, the precise position of POS-1 binding is not known.

POS-1 is one of several nematode CCCH-type tandem zinc finger proteins (hereafter TZF) required for oocyte maturation and early development (Mello et al. 1996; Schubert et al. 2000; Shimada et al. 2006; Shirayama et al. 2006). These proteins are related to tristetraprolin (TTP), a mammalian factor that promotes the deadenylation and subsequent rapid turnover of tumor necrosis factor $\alpha$ (TNF $\alpha)$ mRNA by direct association with its $3^{\prime}$-UTR (Carballo et al. 1998; Lai et al. 1999, 2005). TTP binds to the sequence UUAUUUAUU, present in multiple copies within the AU-rich element (ARE) of the TNF $\alpha 3^{\prime}$-UTR, with high affinity and specificity (Worthington et al. 2002; Blackshear et al. 2003; Brewer et al. 2004). In contrast, the nematode TZF protein MEX-5, required for anterior development, binds with high affinity but relaxed specificity to uridine-rich sequences (Schubert et al. 2000; Pagano et al. 2007). Little is known about the binding specificity of the other members of the nematode TZF protein family, including POS-1. To probe the basis for specific mRNA recognition by POS- 1 and to facilitate prediction of novel POS-1 regulatory targets, we set out to delineate the RNAbinding specificity of this protein.

\section{RESULTS}

\section{POS-1 binds weakly to TTP and MEX-5 binding sites}

We first asked whether POS-1 binds to RNA with the same specificity as TTP or MEX-5. Recombinant POS-1 TZF domain (amino acids 80-180) was expressed as a Cterminal fusion to maltose binding protein (MBP) in 
Escherichia coli and purified to near homogeneity. The recombinant protein was used in quantitative electrophoretic mobility shift assays (EMSA) with fluorescein endlabeled RNAs encoding high affinity binding sequences recognized by TTP or MEX-5: ARE13 and poly(U)-13, respectively (Fig. 2A,B; Brewer et al. 2004; Pagano et al. 2007). Varying concentrations of POS-1 were equilibrated with trace labeled RNA, and the bound RNA was resolved from the free RNA by gel electrophoresis. The fraction of bound RNA at each concentration of POS-1 was determined using a FUJI FLA-5000 fluorimager and the apparent equilibrium dissociation constant $\left(K_{\mathrm{d} \text {,app }}\right)$ was determined by a fit of the data to the Hill equation. POS-1 binds to ARE13 with modest affinity $\left(K_{\mathrm{d}, \mathrm{app}}=200 \pm 6 \mathrm{nM}\right), \sim 50$ times weaker than the previously published affinity of TTP for ARE13 (Brewer et al. 2004). Likewise, POS-1 binds to poly $(\mathrm{U})-13$ RNA $\left(K_{\mathrm{d} \text {,app }}=500 \pm 130 \mathrm{nM}\right)$, but the affinity is reduced compared to MEX-5's affinity for the same sequence (Pagano et al. 2007). Together, the results demonstrate that though POS-1 binds directly to RNA recognized by TTP and MEX-5, it does so with significantly reduced affinity.

\section{POS-1 binds to the 3 '-UTR of multiple genes required for embryogenesis}

We hypothesized that POS-1 binds with higher affinity to a sequence determinant that is different from TTP or MEX-5. In an attempt to identify a high affinity POS-1 interacting

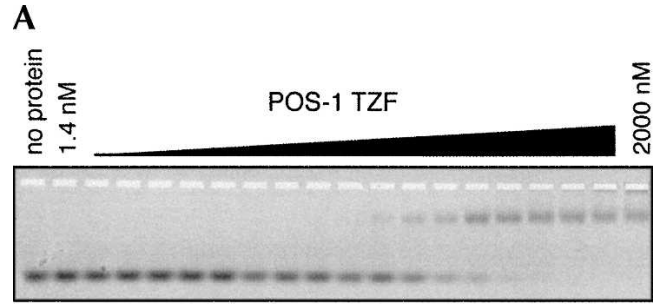

ARE13: AUUUAUUUAUUUA

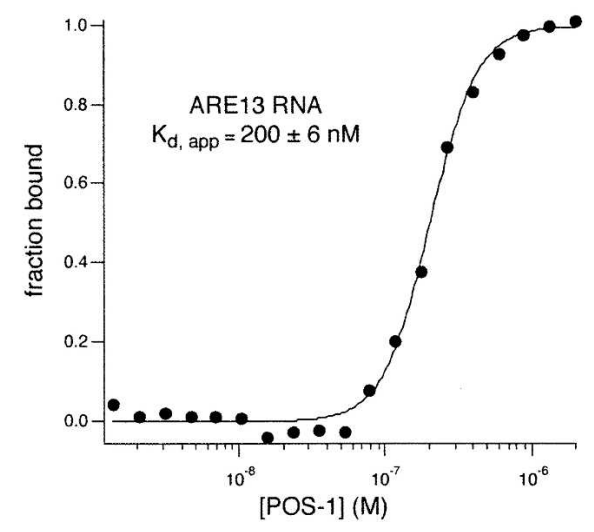

C

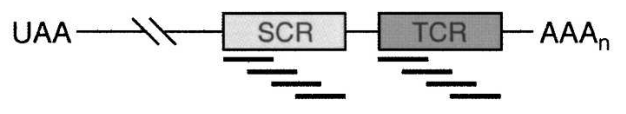

B
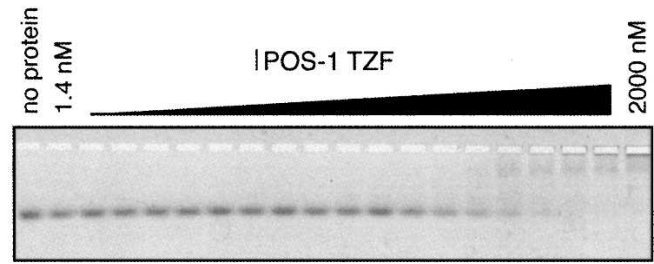

U13: UUUUUUUUUUUUU

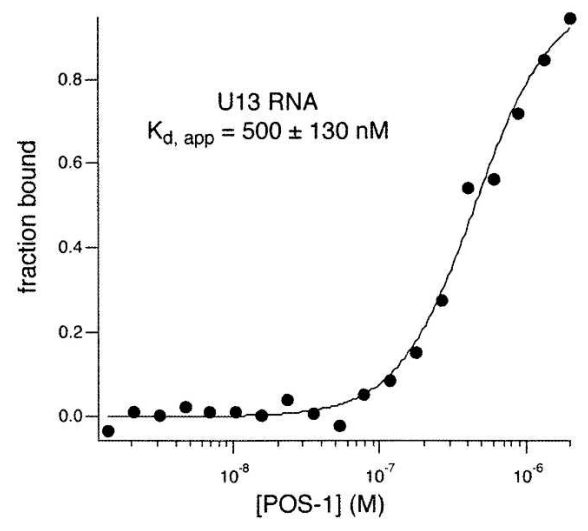

D

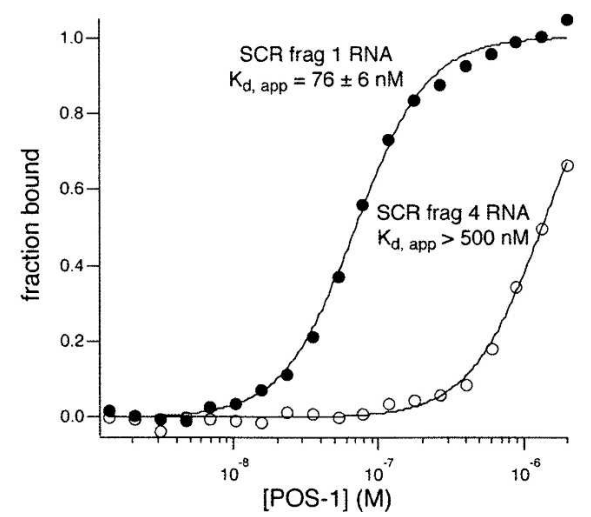

FIGURE 2. POS-1 is a specific RNA-binding protein with a different specificity than either TTP or MEX-5. (A) POS-1 binding to ARE13 was measured by electrophoretic mobility shift assay. A representative gel is shown, with a plot of POS-1 concentration versus fraction bound below. The reported $K_{\mathrm{d} \text {,app }}$ is the average $\pm 1 \mathrm{SD}$ of three independent replicates. (B) POS-1 binding to U13 was measured as in $A$. (C) Schematic of tiled fragments of the $g l p-1$ SCR and TCR. (D) POS-1 binding to fragments one and four of the $g l p-1$ SCR was measured as in A. 
sequence, we constructed a library of tiled fragments of the glp-1 SCR and TCR. These elements were previously demonstrated to associate with POS-1 by yeast three hybrid analysis (Ogura et al. 2003). Each fragment is approximately $30 \mathrm{nt}$ long and overlaps the previous fragment by $15 \mathrm{nt}$ (Fig. 2C). The association of POS-1 with these fragments was assayed by EMSA (Fig. 2D; Table 1). POS-1 binds to three of the four SCR fragments and to all four TCR fragments. The affinity of POS- 1 is highest for the fragment near the $5^{\prime}$ end of the SCR $\left(K_{\mathrm{d} \text {,app }}=76 \pm 6 \mathrm{nM}\right)$ that contains the functional GRE and GDE sequences. The data indicate that one or more high affinity POS-1 binding sites are present in both the SCR and the TCR. However, a comparison of the sequences of each fragment does not easily reveal the determinants of the high affinity interactions.

In a second approach to identify sequences that POS-1 binds with high affinity, we constructed a library of sequences from maternal mRNA 3 '-UTRs that contain at least two UAUU elements (TTP half-sites) with no more than two intervening nucleotides. We rationalized that POS-1 may bind to similar determinants as TTP, but with altered spacing between those determinants due to an increase in the number of amino acids that link the individual zinc fingers (17 in POS- 1 compared with 12 in TTP). The library was biased to include only UTR fragments from genes that are post-transcriptionally regulated during early development (Bowerman et al. 1993; Mello et al. 1994; Draper et al. 1996; Hunter and Kenyon 1996; Gomes et al. 2001). The affinity of POS-1 for each sequence in the library was assayed by EMSA (Table 2). In total, six UTR fragments from five genes (Table 2, apx-1, mex-3, pal$1, s k n-1$, and $s p n-4)$ were tested. POS-1 binds to two of these sequences with high affinity. These include a short fragment of the pal-1 $3^{\prime}$-UTR $\left(K_{\mathrm{d} \text {,app }}=84 \pm 3 \mathrm{nM}\right)$, and a longer fragment of the mex-3 $3^{\prime}$-UTR that contains multiple UA UU sequences (mex-3 fragment: AACUAUUAUUAUUU GUUAUUCAUAUUUU, $K_{\text {d,app }}=47 \pm 7 \mathrm{nM}$ ) (Fig. $3 \mathrm{~A}$ ).

MEX-3 is a $\mathrm{KH}$ domain RNA-binding protein required for specifying the fates of anterior blastomeres during early embryogenesis (Draper et al. 1996). MEX-3 acts by inhibiting the developmental program that specifies body wall muscle. In wild-type embryos, this tissue type is produced exclusively by one of the posterior founder cells, while in mex-3 mutant embryos, it is produced ectopically by descendants of the two-cell stage anterior daughter (Draper et al. 1996). This suggests that MEX-3 functions during the same stage of embryogenesis as POS-1, and also that MEX-3 activity must be restricted to the anterior of the embryo. Consistent with this, both MEX-3 protein and mex-3 mRNA are asymmetrically distributed in the anterior of the embryo at the two- and four-cell stages in a pattern that is anti-correlated with POS-1 (Draper et al. 1996). POS-1 may regulate the expression of mex-3 by repressing its translation, promoting the turnover of mex3 mRNA, or both. To further explore the potential regulatory relationship between POS-1 and mex-3, we decided to further characterize the interaction between mex-3 mRNA and POS-1.

\section{POS-1 forms an equimolar complex with the mex-3 fragment}

POS-1 binds to the mex-3 3'-UTR fragment with the highest affinity of all tested sequences. This could be due to the presence of multiple binding sites, or it might be due to the presence of a single site that binds to POS-1 with higher affinity. To distinguish between these possibilities, the stoichiometry of the complex between POS-1 and this RNA fragment was determined by EMSA (Fig. 3B). Varying concentrations of POS-1 were equilibrated with a fixed, elevated concentration of unlabeled mex-3 RNA supplemented with a trace amount of fluorescently labeled mex-3 RNA. After equilibration, the bound RNA was resolved from the free RNA by gel electrophoresis and the fraction of bound RNA was determined by fluorimetry. The data were fit to a quadratic model of saturable binding (Rambo and Doudna 2004). The apparent stoichiometry of the POS-1:mex-3 complex is one to one (saturation point = $1.0 \pm 0.1$, consistent with the hypothesis that the mex-3 RNA contains a single, high affinity binding site.

TABLE 1. Electrophoretic mobility shift assay with g/p-1 3'-UTR fragments

\begin{tabular}{|c|c|c|c|}
\hline Name & Sequence $^{\mathrm{a}}$ & $\begin{array}{c}K_{\mathrm{d}, \mathrm{app}} \\
(\mathrm{nM})\end{array}$ & $n$ \\
\hline SCR frag 1 & UUAUUCUAGACUAAUAUUGUAAGCUAUAAG & $76 \pm 6$ & 3 \\
\hline SCR frag 2 & AUUGUAAGCUAUAAGUUGUAGAAUAAUUAU & $97 \pm 6$ & 3 \\
\hline SCR frag 3 & UUGUAGAAUAAUUAUUGAUCCAAAUCAGAU & $120 \pm 20$ & 3 \\
\hline SCR frag 4 & UGAUCCAAAUCAGAUUAAGAGUAUAA & $500 \pm 100$ & 3 \\
\hline TCR frag 1 & UUGUUUUUUCUCCUUUUCUUUAUAACUUGU & $150 \pm 20$ & 3 \\
\hline TCR frag 2 & UUUCUUUAUAACUUGUUACAAUUUUUGAAA & $120 \pm 20$ & 3 \\
\hline TCR frag 3 & UUACAAUUUUUGAAAUUCCCUUUUUUGACA & $310 \pm 30$ & 3 \\
\hline TCR frag 4 & UUCCCUUUUUUGACAGGCUUUUAUUACACUGUAA & $189 \pm 7$ & 3 \\
\hline
\end{tabular}


TABLE 2. Electrophoretic mobility shift assay with maternal mRNA fragments

\begin{tabular}{|c|c|c|c|}
\hline Name & Sequence ${ }^{a, b}$ & $\begin{array}{c}K_{\mathrm{d}, \mathrm{app}} \\
(\mathrm{nM})\end{array}$ & $n$ \\
\hline apx-1 frag & GUUUAUUUUUAUUAU & $120 \pm 10$ & 3 \\
\hline pal-1 frag 1 & AUUUAUUAUAUUUU & $167 \pm 6$ & 3 \\
\hline pal-1 frag 2 & CUUUAUUUAUUGU & $84 \pm 3$ & 3 \\
\hline skn-1 frag & AGU $\underline{\cup A \cup U U C \underline{U A U U A U}}$ & $130 \pm 30$ & 3 \\
\hline spn-4 frag & ACGUAUUGUAUUUU & $250 \pm 20$ & 3 \\
\hline mex-3 frag & AAC $\underline{\cup A U U A U U A U U U G U \underline{U A U}} \underline{U} \underline{\cup A U U U U}$ & $47 \pm 7$ & 3 \\
\hline poly $(C)-15$ & ССССССССССССССС & $>1000$ & 1 \\
\hline
\end{tabular}

aUnderline denotes TTP half-site.

boldface denotes PRE.

to monitor POS-1 binding in real time. The apparent equilibrium dissociation constant was determined by plotting polarization as a function of protein concentration and fitting the data to the Hill equation (Fig. 4C). The $K_{\mathrm{d} \text {,app }}$ of POS- 1 for mex-3 RNA is $52 \pm 4 \mathrm{nM}$, similar to the $K_{\mathrm{d} \text {,app }}$ determined by EMSA.

Next, the polarization assay was used to determine the dissociation kinetics of the complex. An excess of unlabeled mex-3 min RNA, poly(C)-15 RNA, or a buffer control was added to a pre-

To ensure that POS- 1 binds as a monomer, the oligomerization state of recombinant POS- 1 was determined by size exclusion chromatography and by equilibrium sedimentation ultracentrifugation (Fig. 3C,D). Both methods reveal that POS-1 is predominantly monomeric, even at a concentration near $20 \mu \mathrm{M}$, orders of magnitude higher than the apparent dissociation constant for the mex-3 RNA. We conclude that monomeric POS-1 binds to the mex-3 3 '-UTR fragment with high affinity as a one to one molar stoichiometric complex.

\section{POS-1 recognizes a 12-nucleotide fragment within the mex-3 UTR}

To identify the minimal POS- 1 binding site within the mex-3 3'-UTR fragment, three overlapping 15-nucleotide subfragments of this RNA were synthesized. The affinity of each for POS-1 was determined by EMSA (Fig. 4A). POS-1 binds to fragments 1 and 2 slightly weaker than the intact sequence (Fig. 4A, mex-3 fragment $1, K_{\mathrm{d} \text {,app }}=110$ $\pm 40 \mathrm{nM}$; mex-3 fragment $2, K_{\mathrm{d} \text {,app }}=89 \pm 5 \mathrm{nM}$ ). In contrast, POS-1 binds to fragment 3 with drastically reduced affinity (Fig. 4A, mex-3 framgent $3, K_{\mathrm{d}, \text { app }}=$ $800 \pm 200 \mathrm{nM}$ ). This suggests that a high affinity POS-1 binding site is located in the overlap between the first and second mex-3 fragments. To test this hypothesis, a 12-nt fragment that corresponds to this overlap (hereafter, mex$3 \mathrm{~min}$ ) was synthesized. This sequence binds with identical affinity, within error, to the original mex-3 RNA (Fig. 4A, mex-3 min, $K_{\mathrm{d} \text {,app }}=39 \pm 6 \mathrm{nM}$; $m e x-3 \mathrm{RNA}, K_{\mathrm{d} \text {,app }}=47 \pm$ 9 nM; Fig. 4B).

To confirm the equilibrium dissociation constant for mex-3 min and to develop a convenient assay for kinetic analysis, we assessed the ability of POS-1 to change the polarization of fluorescein end-labeled mex-3 min RNA in solution. Varying concentrations of protein were equilibrated with limiting labeled mex-3 min RNA, and the polarization value was determined using a fluorescence plate reader. The association of POS-1 with the fluorescently labeled mex-3 min RNA significantly increases the polarization of the fluorophore, thus providing a parameter formed complex of POS-1 and labeled mex-3 min RNA (Fig. 4D). Unlabeled mex-3 min serves as a trap to prevent re-association with the labeled RNA over the time course of the experiment. Unlabeled poly(C)-15 RNA does not bind to POS-1 (Table 2), and serves as a nonspecific binding control. To control for dissociation due to dilution, an experiment was performed with buffer in place of the unlabeled RNA. The apparent dissociation rate constant $\left(k_{\text {off,app }}\right)$ was determined by fitting the observed change in polarization as a function of time to an exponential decay. The $k_{\text {off,app }}$ is $2.94 \pm 0.08 \times 10^{-3} \mathrm{sec}^{-1}$ when unlabeled mex-3 $\mathrm{min}$ is used as a competitor. In contrast, little dissociation is observed when poly $(\mathrm{C})-15$ or buffer alone is added. Based on these measurements, and the determination of the $K_{\mathrm{d} \text {,app }}$ above, the association rate constant can be calculated $\left(k_{\text {on,calc }}=6.0 \pm 0.4 \times 10^{4} \mathrm{M}^{-1} \mathrm{sec}^{-1}\right)$. These results provide a kinetic and thermodynamic framework for detailed analysis of the interaction between POS-1 and the minimal mex-3 fragment.

\section{Determination of the POS-1 consensus sequence}

Next, we set out to determine the sequence determinants within mex-3 min that contribute to binding. To do this, the change in the standard free energy change $\left(\Delta \Delta \mathrm{G}^{\circ}\right)$ was measured for every single point mutation of mex-3 min RNA using EMSA. In total, 36 individual mutations were tested, representing every possible single nucleotide substitution at each position of the mex-3 min sequence (Fig. 5A). Mutation of seven positions causes a significant decrease in affinity (Fig. 5A, positions 2-7,10: $\Delta \Delta \mathrm{G}^{\circ}>0.5 \mathrm{kcal} / \mathrm{mol}$ ), while five positions can tolerate any base substitution (Fig. $5 \mathrm{~A}$, positions $\left.1,8,9,11,12: \Delta \Delta \mathrm{G}^{\circ}<0.5 \mathrm{kcal} / \mathrm{mol}\right)$. Based on these data, the POS-1 recognition element (PRE) is UAUURDNNG, where $\mathrm{R}$ is any purine, $\mathrm{D}$ is $\mathrm{A}, \mathrm{G}$, or $\mathrm{U}$, and $\mathrm{N}$ is any base. Compared with the TTP binding site, the PRE contains an extra purine and displays a greater degree of degeneracy (Brewer et al. 2004). In contrast with the MEX-5 binding sequence, the PRE exhibits strict requirements at several positions, while MEX-5 binds to any uridine-rich sequence (Pagano et al. 2007). The disparity 
A

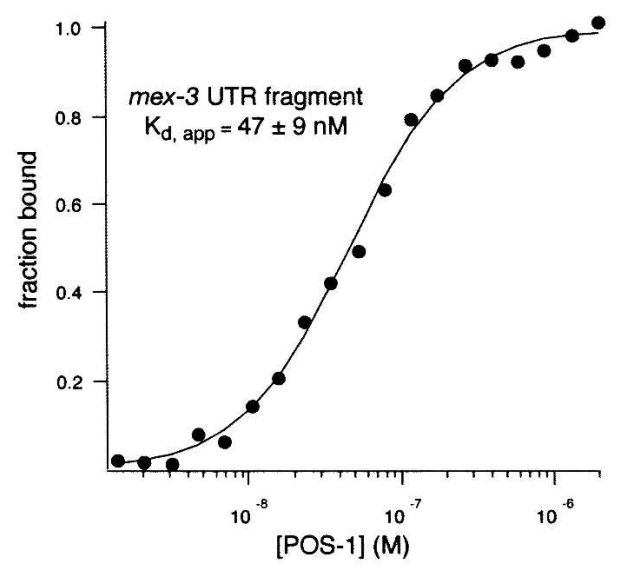

C

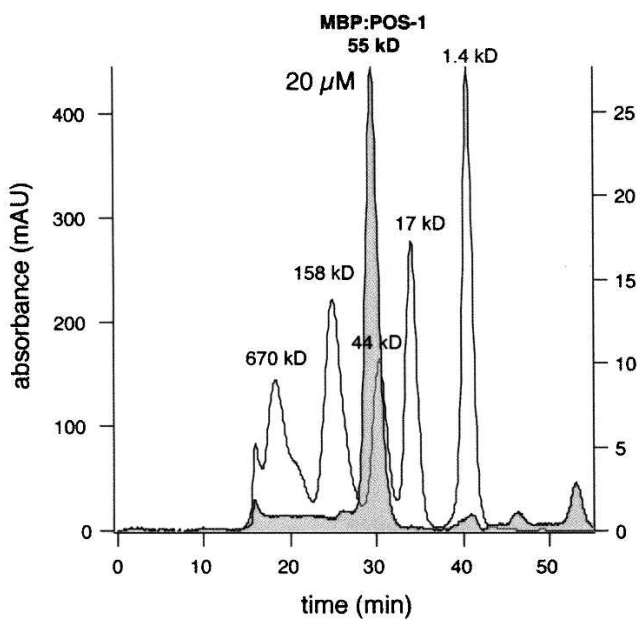

B

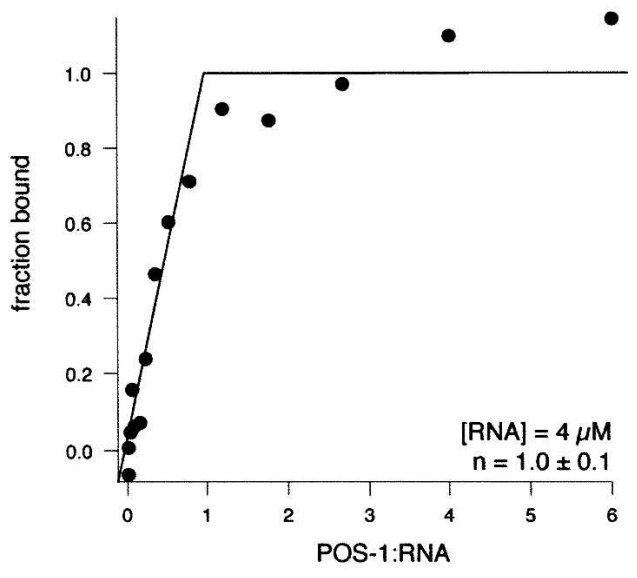

D

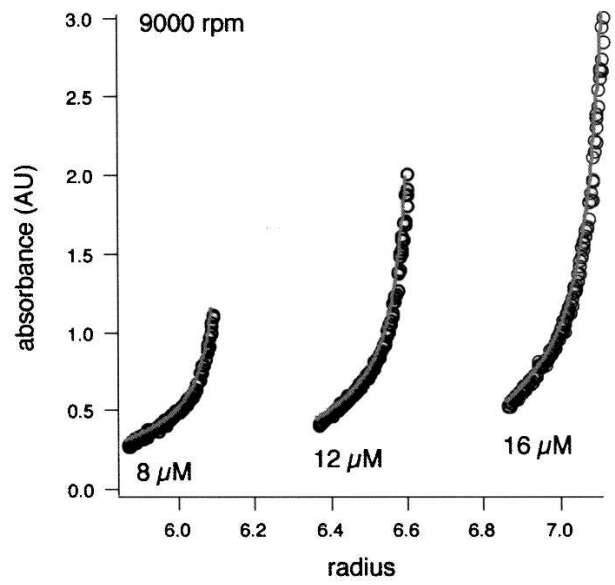

FIGURE 3. POS-1 binds to the mex- 3 UTR fragment with apparent $1: 1$ stoichiometry. ( $A$ ) POS-1 binding to the mex- 3 UTR fragment was measured as in Figure 1A. (B) Stoichiometric binding assay between POS-1 and mex-3 RNA. The total RNA concentration for the experiment is indicated. The molar equivalent point $(n)$ was determined from a quadratic fit (Rambo and Doudna 2004). (C) Gel filtration chromatogram of recombinant POS-1. Gel filtration standards are displayed in white. Molecular weights of each standard peak are indicated. POS-1 elution profile is displayed in gray, and the protein concentration and apparent molecular weight are indicated. (D) Equilibrium analytical ultracentrifugation traces of recombinant POS-1. The rate of rotation as well as the protein concentration for each trace are indicated. Gray lines represent the fit to a monomer-Nmer equilibrium.

in specificity between POS-1, TTP, and MEX-5 suggests that the POS-1-RNA interface is significantly different from those of the other proteins.

To investigate the spacing requirements between each of the purines in the PRE, the relative position of each purine nucleotide was varied within a polyuridine background, and the $\Delta \Delta \mathrm{G}^{\circ}$ for each mutant sequence was determined by EMSA (Fig. 5B). POS-1 is tolerant of an additional nucleotide between $\mathrm{A} 3$ and $\mathrm{A} 6$, and one additional or one fewer nucleotide between A6 and G10. Taking the flexibility of the spacing between purines into account, we expand the PRE to $5^{\prime}-\mathrm{UA}\left(\mathrm{U}_{2-3}\right) \mathrm{RD}\left(\mathrm{N}_{1-3}\right) \mathrm{G}-3^{\prime}$. This consensus is present in all tested sequences that bind to POS-1 with high affinity, including fragments from the pal-1 and $g l p-13^{\prime}$ UTRs (pal-1 fragment 2, $K_{\mathrm{d} \text {,app }}=84 \pm 3 \mathrm{nM}$; $g l p-1$ SCR fragment $1, K_{\mathrm{d}, \text { app }}=76 \pm 6 \mathrm{nM}$ ).

\section{The PRE is necessary but not sufficient to pattern the expression of a reporter}

Work from Marin and Evans (2003) identified a 34-nt fragment of the $g l p-1$ SCR that is sufficient to confer patterned embryonic expression on a reporter gene. Contained within this fragment are two subelements, the GRE and GDE, which are required for translational repression and de-repression of a $g l p-1$ reporter in early embryos, respectively. Here, we show that the GDE and the PRE are one and the same, and that POS-1 binds to this element with high affinity. A 5-nt substitution within the PRE prevents expression of the reporter protein without changing the expression of the reporter mRNA (Fig. 6A; Marin and Evans 2003). This indicates that the PRE is required for the post-transcriptional regulation of $g l p-1$ mRNA during 
A

\begin{tabular}{lll} 
& sequence & $\mathrm{K}_{\mathrm{d}, \text { app }}(\mathrm{nM})$ \\
\hline mex-3 UTR fragment & AACUAUUAUUAUUUGUUAUUCAUAUUUU & $47 \pm 9$ \\
mex-3 subfrag 1 & AACUAUUAUUAUUUG & $110 \pm 40$ \\
mex-3 subfrag 2 & UUAUUAUUUGUUAUUCA & $89 \pm 5$ \\
mex-3 subfrag 3 & UGUUAUUCAUAUUUU & $800 \pm 200$ \\
mex-3 min & UUAUUAUUUGUU & $39 \pm 6$
\end{tabular}

B
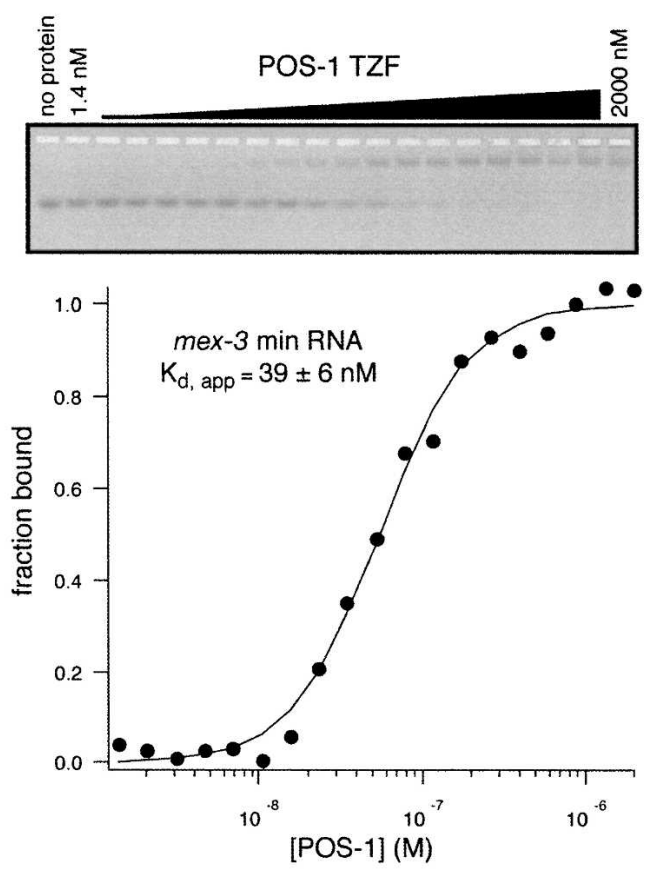

C
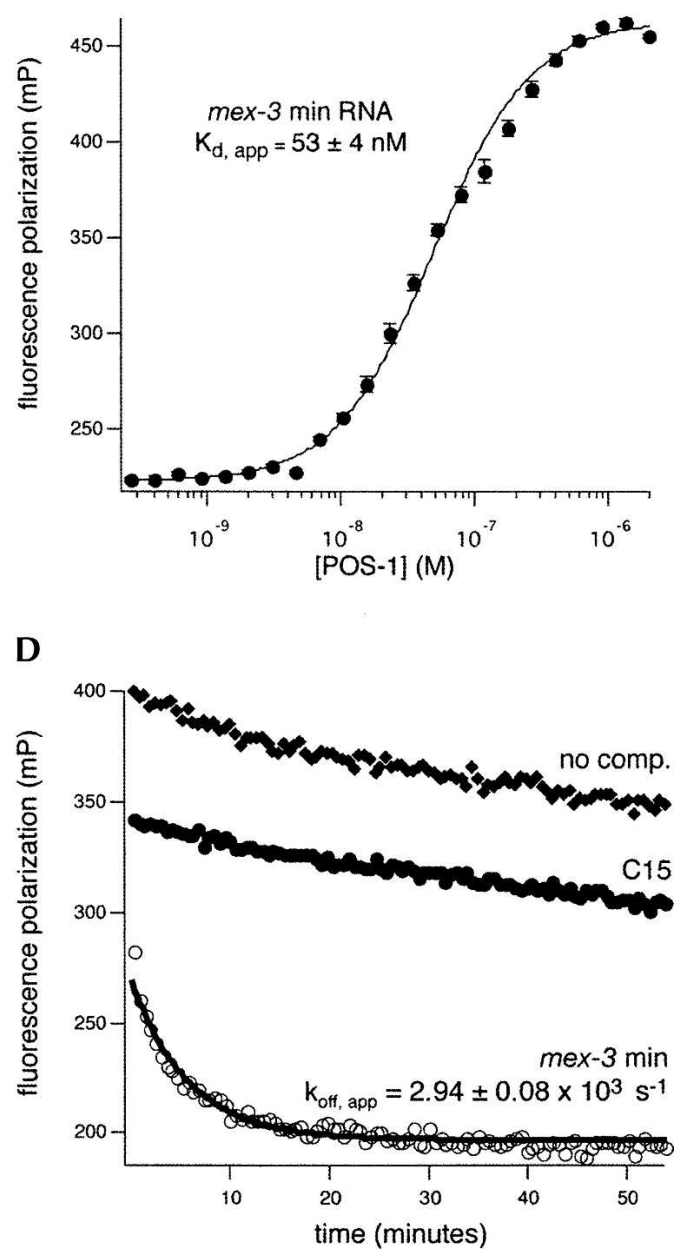

FIGURE 4. POS-1 specifically recognizes a 12-nucleotide fragment of the mex-3 3 '-UTR. (A) Table of association measurements for POS-1 and mex-3 fragments. $K_{\mathrm{d} \text {,app }}$ was measured by electrophoretic mobility shift assay, and the reported values are the average \pm SD for three independent replicates. The mex-3 min sequence is highlighted in gray. $(B)$ Representative electrophoretic mobility shift assay for $m e x-3$ min. The fit and reported $K_{\mathrm{d} \text {,app }}$ are as in Figure 1A. $(C)$ Representative fluorescence polarization assay for mex-3 min. Each data point is the average \pm SD of five reads of an independent replicate. The data were fit to the Hill equation, and the reported $K_{\mathrm{d} \text {,app }}$ is the average $\pm \mathrm{SD}$ of three independent replicates. $(D)$ Representative kinetic fluorescence polarization assays for POS-1 and the indicated RNAs. $k_{\text {off,app }}$ was determined by monitoring the change in fluorescence polarization after the addition of a 100-fold excess of unlabeled competitor RNA, and fitting to a single exponential. Empty circles indicate unlabeled mex-3 min competitor; filled circles, unlabeled C15 competitor; filled diamonds, no competitor; and solid black line represents the single exponential fit.

early embryogenesis and suggests that it may play a functional role in the regulation of other genes during the same period.

To test if the PRE alone is sufficient to confer patterned expression to a reporter, we generated a strain that expresses GFP from the pie-1 promoter where six tandem copies of the mex-3 min sequence were inserted into the pie-1 3'-UTR (Fig. 6B). This UTR does not cause asymmetric expression of reporter transcripts in embryos (Reese et al. 2000) and, as such, provides a neutral background to test the role of exogenous cis-acting elements. If the PRE is sufficient to cause POS-1-mediated negative regulation, we expect to see a GFP expression pattern that anti-correlates with POS-1. Instead, the transgenic worms express GFP throughout the syncytial germline, in oocytes, and in all cells of the early embryo. This finding suggests that the PRE alone, and thus POS-1 binding alone, is not sufficient to drive UTR-dependent regulation and may require additional factors for post-transcriptional regulation of specific targets.

\section{Prevalence of the PRE in C. elegans $3^{\prime}$-UTRS}

In order to establish a list of candidate POS-1 regulatory targets, we used the pattern matching tool PATSCAN to locate the PRE consensus within all annotated 3'-UTRs retrieved from Wormbase release WS180 (Dsouza et al. 1997). Of the 10,201 $3^{\prime}$-UTRs retrieved, 2902 (28.4\%) 


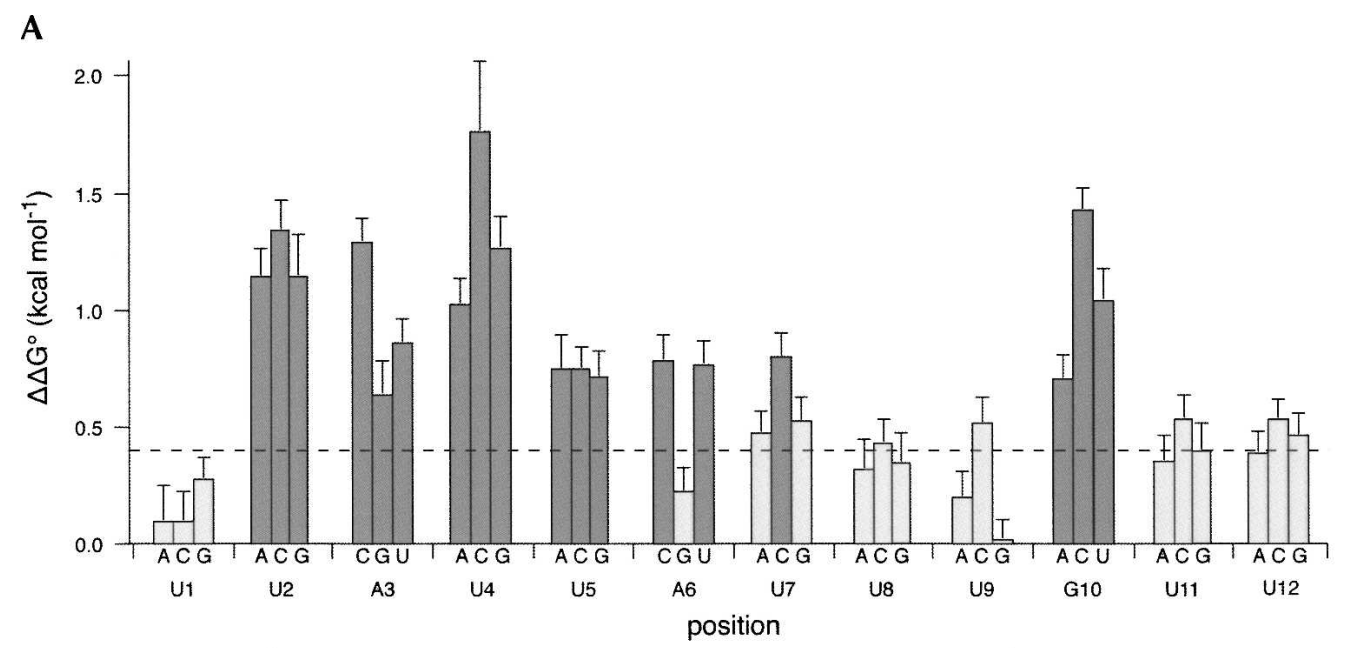

\section{B}
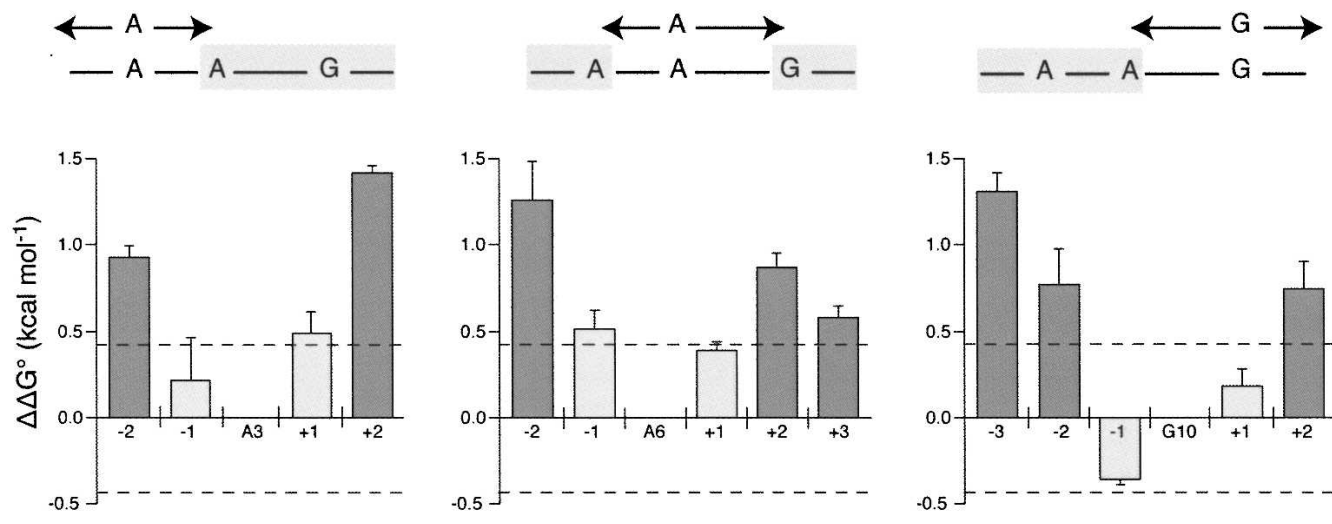

position

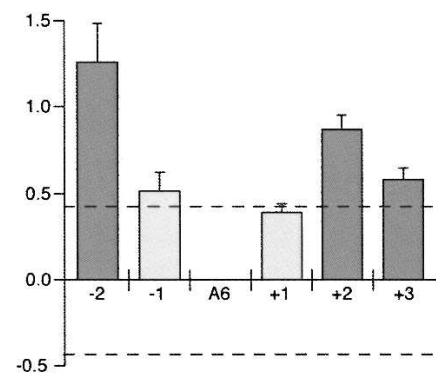

position

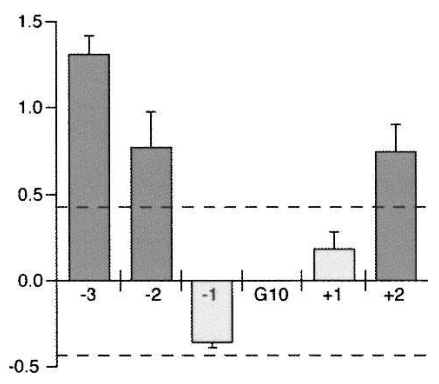

position

FIGURE 5. POS-1 recognizes the sequence $\mathrm{UA}\left(\mathrm{U}_{2-3}\right) \mathrm{RD}\left(\mathrm{N}_{1-3}\right) \mathrm{G}$. (A) Systematic mutagenesis of mex-3 min. The $K_{\mathrm{d} \text {,app }}$ for each mutation of mex-3 min was measured by electrophoretic mobility shift assay and compared to the previously measured $K_{\mathrm{d} \text {,app }}$ for mex-3 min to determine the change in standard change of free energy $\left(\Delta \Delta \mathrm{G}^{\circ}\right)$. Each bar represents the $\Delta \Delta \mathrm{G}^{\circ}$ caused by the base substitution indicated on the $x$-axis. Substitutions that cause a greater than $0.4 \mathrm{kcal} / \mathrm{mol}$ (dotted line, approximately twofold difference in $K_{\mathrm{d} \text {,app }}$ ) change in standard free energy are shown in dark gray. Error bars are the propagation of error derived from the standard deviations of three replicates each of mex-3 min and the indicated base substitution. (B) Spacing mutagenesis of mex-3 min. The $K_{\mathrm{d} \text {,app }}$ for a series of double mutations that switch the position of the indicated purine with either an upstream or downstream uracil was measured as in $A$. Each bar represents the $\Delta \Delta \mathrm{G}^{\circ}$ caused by one double mutation, determined as in $A$. Double mutations that cause a greater than $0.4 \mathrm{kcal} / \mathrm{mol}$ change in standard free energy are shown in dark gray.

contain at least one POS-1 binding site. Because POS-1 is expressed only in early embryos and because pos-1 mutant embryos have a maternal effect lethal phenotype (Tabara et al. 1999), it is expected that critical POS- 1 regulatory targets will be (1) expressed in early embryos and (2) required for early embryogenesis. Of the 2902 genes that contain a predicted POS-1 binding site, 227 are expressed in one- to eight-cell embryos (Baugh et al. 2003) and result in embryos that fail to hatch when silenced by RNAi (Fig. 7A; Supplemental Table 1; Sonnichsen et al. 2005). We propose that these represent the most likely candidate POS- 1 targets relevant to its roles in embryonic patterning.

In addition to $g l p-1$, mex -3 , and pal- 1 , a number of genes required for establishing and maintaining the anteriorposterior axis (par-1, par-3, and par-5) (Cuenca et al. 2003) and specifying intestinal fate (mom-2, mom-5, and $s k n-1)$ (Rocheleau et al. 1997; Thorpe et al. 1997; Maduro et al. 2001) contain at least one PRE within their $3^{\prime}$-UTR. Intriguingly, the pos-1 $3^{\prime}$-UTR also has a PRE, suggesting that POS-1 may play a role in regulating its own expression. Neither apx-1 nor nos-2, two genes whose expression patterns are perturbed in pos-1 mutants, contains a predicted POS-1 binding site in its $3^{\prime}$-UTRs, suggesting that the role of POS-1 in regulating these genes may be indirect.

To determine if the POS- 1 consensus sequence is statistically underrepresented, we generated 100 randomized artificial 3'-UTR libraries and determined the frequency of the PRE in each. The artificial libraries were generated using a Markov chain based on the dinucleotide 
A

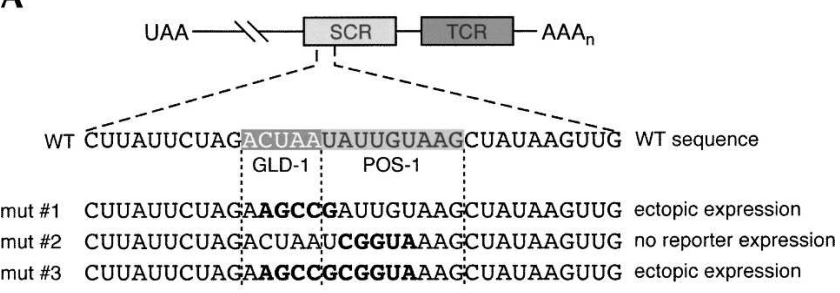

B
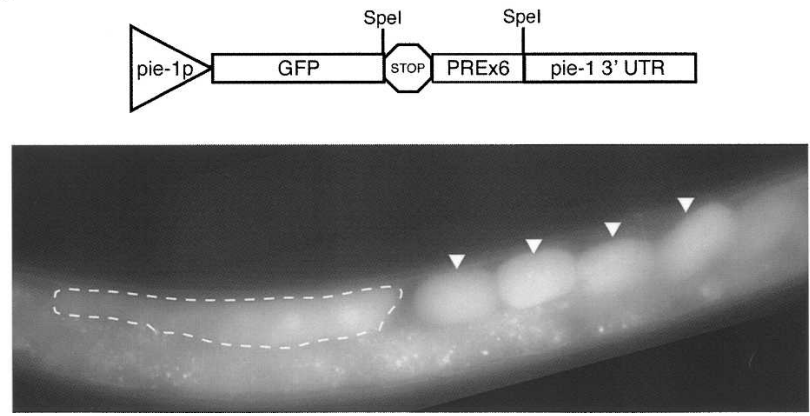

FIGURE 6. The PRE is necessary but not sufficient for patterned regulation of a reporter. (A) Previously published mutational analysis of the $g l p-1$ SCR revealed two regulatory elements corresponding to predicted POS-1 and GLD-1 binding sites. (Above) Schematic representation of POS-1 and GLD-1 binding sites within the $g l p-1$ SCR. (Below) Mutations previously made within these binding sites and their corresponding effect on the expression of a reporter, from Marin and Evans (2003). (B) 6XPRE GFP reporter strain. Above is a schematic of the reporter construct, below is a widefield epifluorescence image of an adult hermaphrodite. The oocyte region is boxed with a dashed line, and embryos are marked with arrows. GFP expression is uniform throughout early embryos.

frequencies observed in embryonic 3'-UTRs (Fig. 7B). Dinucleotides were used instead of mononucleotides because a number of dinucleotides occurred more or less frequently than would be expected on the basis of the mononucleotide frequencies alone. The average and standard deviation of the PRE frequency in the 100 artificial libraries establishes the expected number and variance of the PRE associated with random chance. The ratio of the number of actual occurrences to the number of expected occurrences defines the extent to which the PRE is over- or underrepresented.

There are 2314 occurrences of the PRE in the $3^{\prime}$-UTRs of early embryonic transcripts. In contrast, there are $1530 \pm 40$ PRE occurrences in the set of 100 artificial $3{ }^{\prime}$-UTRs. Thus, the PRE is $1.51 \pm 0.04$ fold overrepresented in real embryonic $3^{\prime}$-UTR sequences. This finding is consistent with the hypothesis that POS-1 requires additional specificity factors in order to choose appropriate targets for regulation or, alternatively, that the network of targets regulated by POS-1 is much larger than previously anticipated.

\section{DISCUSSION}

Using in vitro biochemical techniques, we have determined that the C. elegans TZF protein POS-1 is a sequence-specific
RNA-binding protein that binds to RNA with novel specificity. POS-1 binds with highest affinity the sequence $\mathrm{UA}\left(\mathrm{U}_{2-3}\right) \mathrm{RD}\left(\mathrm{N}_{1-3}\right) \mathrm{G}$, and with moderate affinity to other sequences containing ARE-like elements. Compared with the related TZF proteins TTP and MEX-5, POS-1 binds to RNA with different specificity, demonstrating that this RNA-binding protein family is capable of binding to diverse sequence determinants. TTP recognizes the sequence UUAUUUAUU (Brewer et al. 2004), while MEX-5 recognizes any sequence with six to eight uridines within an 8-nt window (Pagano et al. 2007). The difference of a single amino acid in each zinc finger, required for specific recognition of each of the two adenosines in the TTP recognition element (Hudson et al. 2004), is sufficient to account for the differences between TTP and MEX-5 specificity (Pagano et al. 2007). Accordingly, the identity of these residues is different in POS-1 compared with either MEX-5 or TTP, suggesting that these amino acids also contribute to the difference in POS-1 specificity. However, POS-1 recognizes three purines compared with two in the TTP binding site, indicating that it must have a third purine recognition site. More work, including structural studies, will be required to understand the molecular basis of differential RNA recognition by POS-1.

The PRE occurs in the $3^{\prime}$-UTR of 227 genes expressed in early embryos and required for embryogenesis. These include mom-2, mom-5, and skn-1, all of which are required for the specification of endoderm at the four-cell stage. mom-2 and mom-5 encode Wnt and Frizzled homologs, respectively, cell signaling factors that are required to induce endoderm differentiation (Thorpe et al. 1997). skn-1 encodes a transcription factor that is required to activate the zygotic transcription of genes that promote endoderm fate (Bowerman et al. 1993; Maduro et al. 2001). pos-1 mutants lack endoderm, suggesting that deregulation of some or all of these mRNAs leads to the failure in endoderm specification. The PRE is also found in the 3 '-UTR of par-1, par-3, and par-5, genes essential for the establishment of the anteriorposterior axis in the early embryo. POS-1 is not translated until after the anterior-posterior axis has been established, which argues that it cannot play a primary role in establishing this axis. However, the axis must be maintained following establishment, and POS-1 could play a role in this pathway. Maintenance of the anterior-posterior axis requires MEX-5 (Cuenca et al. 2003), which restricts the expression of POS-1 to the posterior of the early embryo. If POS-1 regulates par gene expression, then MEX-5 could maintain axis polarization through its molecular function of spatially restricting POS-1.

The PRE lies within a 34-nucleotide region of the $g l p-1$ $3^{\prime}$-UTR that is required for translational regulation in early embryos (Marin and Evans 2003), and mutations that directly target the PRE abolish expression of a reporter gene, demonstrating that the PRE is a functional cis-acting regulatory element required to pattern $g l p-1$ expression. 
A

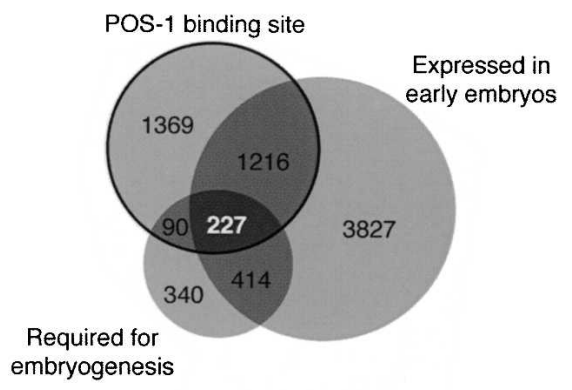

Candidate
POS-1 targets $16166 \quad 2293 \quad \begin{gathered}\text { GLD-1 } \\ \text { binding site }\end{gathered}$
B

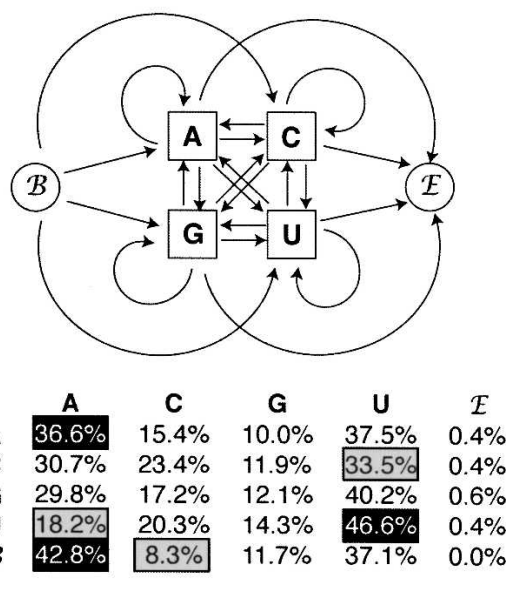

FIGURE 7. The PRE is abundant in C. elegans $3^{\prime}$-UTRs. (A) Bioinformatics analysis of genes containing a PRE in their $3^{\prime}$-UTR. (B) Schematic of the Markov chain used to generate random libraries of $3^{\prime}$-UTRs based on the transit probabilities measured from embryonic $3^{\prime}$ UTRs. Each shape denotes a state, with the script B and E denoting the begin and end states used to model the beginning and the end of random 3'-UTRs, respectively. Arrows represent the transit probabilities from the state the arrow emerges from to the state to which the arrow points. Below are the measured dinucleotide transit probabilities of early embryonic 3'-UTRs. Each entry represents the frequency that the state on the left is followed by the state above. Values with a black background are at least five percent above their corresponding mononucleotide frequencies, while values with a gray background are at least five percent below their corresponding mononucleotide frequencies.

However, the PRE is not sufficient to confer POS-1dependent regulation to an orthogonal 3 '-UTR, indicating that additional cis-acting elements and trans-acting factors are required. One likely candidate is GLD-1 (Lee and Schedl 2001; Ryder et al. 2004). The POS-1 binding site in the $g l p-13^{\prime}$-UTR is immediately adjacent to a binding site for GLD-1. Mutations of either pos-1 or gld-1 result in ectopic GLP-1 expression in all cells of the early embryo, and mutations that disrupt the binding site for either protein lead to aberrant patterning of a reporter (Fig. 6A; Marin and Evans 2003). It is possible that POS-1 and GLD1 may function as a cooperative RNA-binding complex that binds with enhanced specificity to only a small number of mRNAs. Alternatively, antagonistic binding of POS-1 and GLD-1 could modulate the apparent affinity of both proteins, leading to appropriate levels of $g l p-1$ translation. GLD-1 binding sites are present in 66 of the 227 candidate POS-1 targets, suggesting that interplay between these factors might be a general requirement for POS-1 mediated regulation.

The data presented here demonstrate that POS-1 binds to RNA with novel specificity compared with homologous TZF domain proteins, indicating that this fold can evolve to recognize diverse RNA sequences. The relative simplicity of the binding consensus suggests a dichotomy between RNAbinding specificity and selection of specific mRNA targets for regulation. The POS-1 recognition element is necessary but not sufficient to confer patterned expression to a reporter, indicating that additional factors are involved in mRNA target selection. The requirement for recognition by multiple RNA-binding proteins, each with limited sequence specificity, could explain this dichotomy. Our work provides a framework for dissection of the network of maternal transcripts regulated by POS-1 during development and suggests several interesting candidate targets that can explain the phenotypes observed in pos-1 mutants.

\section{MATERIALS AND METHODS}

\section{Cloning of purification of POS-1 80-180 pHMTc}

The sequence encoding amino acids $80-180$ of POS-1 was amplified from the corresponding ORFeome (Open Biosystems) clone via PCR and cloned in frame into the multiple cloning site of pHMTc, a derivative of pMal-c2x (New England Biolabs) that includes an N-terminal 6-his tag and a TEV protease site after MBP (Ryder et al. 2004). This construct was transformed into and expressed in E. coli strain BL21 (DE3) Gold (Stratagene). Protein expression was induced with $1 \mathrm{mM}$ IPTG and $100 \mu \mathrm{M}$ $\mathrm{Zn}(\mathrm{OAc})_{2}$. Cells were lysed and purified using an amylose column (New England Biolabs), followed by HiTrap SP and HiTrap Q (GE Healthcare) columns. Purified POS-1 was dialyzed into storage buffer [ $25 \mathrm{mM}$ Tris-Cl at $\mathrm{pH} 8.0,25 \mathrm{mM} \mathrm{NaCl}, 100$ $\left.\mu \mathrm{M} \mathrm{Zn}(\mathrm{OAc})_{2}, 2 \mathrm{mM} \mathrm{DTT}\right]$, concentrated to $\sim 100 \mu \mathrm{M}$ using a 30,000 MWCO spin concentrator (Vivascience Group), and stored at $4^{\circ} \mathrm{C}$ for up to $2 \mathrm{mo}$.

\section{Preparation of fluorescein-5-thiosemicarbazide labeled RNA}

All RNA oligonucleotides used in this study were chemically synthesized by Integrated DNA Technologies. Oligos were fluorescently labeled at the $3^{\prime}$ end by periodate oxidation followed by reaction with fluorescein-5-thiosemicarbazide as described (Pagano et al. 2007). Labeled RNA was purified away from unreacted label using a Sephadex G-25 spin column (GE Healthcare). Recovered RNA was assayed by agarose gel electrophoresis and UV-Vis spectrophotometry to determine purity and labeling efficiency, respectively. Labeling efficiencies were typically $\sim 70 \%$.

\section{Fluorescent electrophoretic mobility shift assay}

Varying concentrations of purified POS-1 were incubated with $3 \mathrm{nM}$ fluorescently labeled RNA in equilibration buffer for $3 \mathrm{~h}$ at room temperature. Equilibration buffer contained $50 \mathrm{mM}$ Tris (pH 8.0), $100 \mathrm{mM} \mathrm{NaCl}, 0.01 \mathrm{mg} / \mathrm{mL}$ tRNA, $0.01 \%$ (v/v) IGEPAL, and $100 \mu \mathrm{M} \mathrm{ZnOAc} 2$. After $3 \mathrm{~h}, 10 \mu \mathrm{L}$ of $0.005 \%(\mathrm{w} / \mathrm{v})$ bromocresol green in $30 \%$ glycerol was added to $100 \mu \mathrm{L}$ of each 
sample and mixed thoroughly. Fifty microliters of each mixture were loaded onto a $1 \%$ agarose, $1 \times \mathrm{TB}$ gel and run at room temperature for $35 \mathrm{~min}$ at $120 \mathrm{~V}$ to resolve bound from free RNA. Gels were imaged using a Fuji FLA-5000 laser imager to detect the fluorescently labeled RNA. The fraction of bound RNA was determined by taking the ratio of bound signal to total signal. This was plotted against the total protein concentration and fit to the Hill equation to determine the apparent dissociation constant:

$$
\theta=\frac{\left([P]_{t}\right)^{n}}{\left([P]_{t}\right)^{n}+\left(K_{\mathrm{d}, \mathrm{app}}\right)^{n}},
$$

where $\theta$ is the measured fraction RNA bound, $[P]_{t}$ is the total protein concentration, $K_{\mathrm{d} \text {,app }}$ is the apparent dissociation constant, and $n$ is the Hill coefficient. Stoichiometric binding assays were conducted in a similar fashion, except unlabeled RNA was added to a final RNA concentration of $4 \mu \mathrm{M}$, and the data were fit to the following equation (Rambo and Doudna 2004):

$$
\theta=\frac{r+K_{\mathrm{d}, \mathrm{app}}+n-\sqrt{\left(r+K_{\mathrm{d}, \mathrm{app}}+n\right)^{2}-4 r n}}{2 n},
$$

where $\theta$ and $K_{\mathrm{d} \text {,app }}$ are as above, $r$ is the molar ratio of protein to RNA, and $n$ is the molar equivalence point. The $\Delta \Delta \mathrm{G}^{\circ}$ at $20^{\circ} \mathrm{C}$ for each of the mutants of mex-3 min was determined using the following equation:

$$
\Delta \Delta \mathrm{G}^{\circ}=-R T \cdot \ln \left(\frac{K_{\mathrm{d}, \mathrm{app}} m e x-3 \mathrm{~min}}{K_{\mathrm{d}, \mathrm{app}} m u t}\right),
$$

where $R$ is the gas constant and $T$ is the temperature.

\section{Gel filtration chromatography}

The apparent molecular weight of POS-1 80-180 pHMTc relative to standards was determined using a Superdex 200 10/300 GL gel filtration column (GE Healthcare). Approximately $50 \mu \mathrm{L}$ of 20 $\mu \mathrm{M}$ POS-1 were loaded on a column equilibrated with $50 \mathrm{mM}$ Tris ( $\mathrm{pH} \mathrm{8.0),} 300 \mathrm{mM} \mathrm{NaCl}$, and the absorbance at $280 \mathrm{~nm}$ was monitored. The apparent molecular weight of POS-1 was determined by comparing the elution volume to the elution volume for molecular weight standards.

\section{Equilibrium analytical ultracentrifugation}

Three concentrations of POS- $1(8 \mu \mathrm{M}, 12 \mu \mathrm{M}$, and $16 \mu \mathrm{M})$ were centrifuged at $9000,12,000$, and $16,000 \mathrm{rpm}$, and absorbance across the cell at $280 \mathrm{~nm}$ was monitored using a Beckman Optima XL-I analytical ultracentrifuge. Samples were centrifuged until equilibrium had been reached. The resulting traces were fit to the following equation describing a monomer/n-mer transition:

$$
\begin{aligned}
A & =\sqrt{a^{2}} \cdot f \cdot e^{\left[\frac{\omega^{2}}{2 R T} \cdot M(1-\bar{\nu} \rho)\left(r^{2}-r_{0}^{2}\right)\right]} \\
& +(1-f) \cdot e^{\left[\frac{\omega^{2}}{2 R T} \cdot n M(1-\bar{\nu} \rho)\left(r^{2}-r_{0}^{2}\right)\right]},
\end{aligned}
$$

where $A$ is the measured absorbance, $a$ is a scaling factor, $f$ is the fraction of protein in the monomeric state, $\omega$ is the angular velocity, $R$ is the gas constant, $T$ is the temperature, $M$ is the molecular mass of the protein, $n$ is the apparent stoichiometry of the complex, $v$ is the viscosity of solution, $\rho$ is the density of solution, $r$ is the cuvette radius, and $r_{0}$ is a reference distance.

\section{Fluorescence anisotropy assay}

Varying concentrations of POS-1 and $4 \mathrm{nM}$ fluorescently labeled RNA were equilibrated as described in the EMSA section. Following equilibration, each sample was excited with linearly polarized light, and the parallel and perpendicular fluorescence intensities were measured five times each using a Victor ${ }^{3} 1420$ Multilabel Counter (Perkin-Elmer) and the apparent polarization determined. Polarization was plotted against total protein concentration, and fit to the Hill equation as above.

\section{Dissociation rate kinetics}

Binding reactions containing $100 \mathrm{nM}$ POS- 1 and $4 \mathrm{nM}$ fluorescently labeled mex-3 min were equilibrated in conditions described above for $30 \mathrm{~min}$. Following equilibration, samples were transferred to a 96-well FluoTrak plate (Grenier) containing unlabeled competitor RNA and rapidly mixed. Immediately following addition to competitor RNA, the fluorescence polarization of the sample was measured every $20 \mathrm{sec}$ as described above. Fluorescence polarization measurements were plotted against time and fit to the following single exponential decay to determine the apparent dissociation rate constant:

$$
P=P_{0}+A \cdot e^{\left(-k_{\mathrm{off}, \mathrm{app}} \cdot t\right)}
$$

where $P$ is the measured fluorescence polarization, $P_{0}$ is the baseline fluorescence polarization, $A$ is the polarization at $t=0$, $k_{\text {off,app }}$ is the apparent dissociation rate constant, and $t$ is elapsed time.

\section{Bioinformatics}

$3^{\prime}$-UTR sequences were retrieved from release WS180 of Wormbase (www.wormbase.org) using WormMart. To avoid redundancy in the pool of sequences, only the longest 3 '-UTR for each gene with multiple gene models was used. The pattern matching tool PATSCAN (Dsouza et al. 1997) was used to identify UTRs that contain POS-1 and/or GLD-1 binding sites. Mononucleotide and dinucleotide frequencies were determined using Perl scripts and standard UNIX text processing tools. Random 3'-UTR libraries were constructed via a Markov chain; transit probabilities for each state were determined from the observed dinucleotide distribution and the following equation:

$$
p_{i \rightarrow j}=\frac{\mathrm{d}_{i j}}{\mathrm{D}_{i}}
$$

where $p_{i \rightarrow j}$ is the transit probability from nucleotide $i$ to nucleotide $j, d_{i j}$ is the observed frequency of dinucleotide $i j$, and $\mathrm{D}_{i}$ is the observed frequency of dinucleotides beginning with $i$.

\section{Error analysis}

For electrophoretic mobility shift and fluorescence polarization assays, the reported value is the average of at least three 
independent replicates, and the error is \pm 1 SD. For equilibrium sedimentation experiments, the fit error was determined by plotting the residuals to compare the error distribution of each fitted model.

\section{Reporter strain construction}

The reporter construct was generated by digesting plasmid $\mathrm{pJH}$ 4.52 (a generous gift of Dr. Geraldine Seydoux, Johns Hopkins University) with Spe1, and inserting a synthetic DNA duplex containing $3 \times$ copies of the mex- 3 min sequence flanked by Spe 1 sites. The construct used for all experiments contained two copies of the insert in tandem. The reporter strain was generated by ballistic transformation using unc-119 rescue (Praitis et al. 2001). An equal mixture of the reporter plasmid and pDEST-DD03, which harbors the unc-119 rescuing fragment (a gift of Dr. Marian Walhout, University of Massachusetts Medical School), was used to coat the gold particles. Rescued worms were analyzed for GFP expression pattern by fluorescence microscopy with a Zeiss Axioskop microscope.

\section{SUPPLEMENTAL DATA}

Supplemental material can be found at http://www.rnajournal.org.

\section{ACKNOWLEDGMENTS}

We thank Lisa McCoig for providing the POS-1 expression construct; Kirsten Hagstrom, Nick Rhind, and Marian Walhout for sharing equipment; Geraldine Seydoux and Marian Walhout for plasmids; Masaki Shirayama, Craig Mello, Phil Zamore, Tom Evans, and Kirsten Hagstrom for advice; and Ruth Zearfoss, Karen Mruk, and Melonnie Furgason for comments on the manuscript. This work was funded in part by NIH Grant GM081422 to S.P.R. and by a Basil O'Connor Scholar Award from the March of Dimes to S.P.R.

Received July 7, 2008; accepted September 10, 2008.

\section{REFERENCES}

Artavanis-Tsakonas, S., Rand, M.D., and Lake, R.J. 1999. Notch signaling: Cell fate control and signal integration in development. Science 284: 770-776.

Baugh, L.R., Hill, A.A., Slonim, D.K., Brown, E.L., and Hunter, C.P. 2003. Composition and dynamics of the Caenorhabditis elegans early embryonic transcriptome. Development 130: 889-900.

Blackshear, P.J., Lai, W.S., Kennington, E.A., Brewer, G., Wilson, G.M., Guan, X., and Zhou, P. 2003. Characteristics of the interaction of a synthetic human tristetraprolin tandem zinc finger peptide with AU-rich element-containing RNA substrates. J. Biol. Chem. 278: 19947-19955.

Bowerman, B., Draper, B.W., Mello, C.C., and Priess, J.R. 1993. The maternal gene skn-1 encodes a protein that is distributed unequally in early C. elegans embryos. Cell 74: 443-452.

Brewer, B.Y., Malicka, J., Blackshear, P.J., and Wilson, G.M. 2004. RNA sequence elements required for high affinity binding by the zinc finger domain of tristetraprolin: Conformational changes coupled to the bipartite nature of Au-rich MRNA-destabilizing motifs. J. Biol. Chem. 279: 27870-27877.
Carballo, E., Lai, W.S., and Blackshear, P.J. 1998. Feedback inhibition of macrophage tumor necrosis factor- $\alpha$ production by tristetraprolin. Science 281: 1001-1005.

Cuenca, A.A., Schetter, A., Aceto, D., Kemphues, K., and Seydoux, G. 2003. Polarization of the C. elegans zygote proceeds via distinct establishment and maintenance phases. Development 130: 1255-1265.

D'Agostino, I., Merritt, C., Chen, P.L., Seydoux, G., and Subramaniam, K. 2006. Translational repression restricts expression of the C. elegans Nanos homolog NOS-2 to the embryonic germline. Dev. Biol. 292: 244-252.

Draper, B.W., Mello, C.C., Bowerman, B., Hardin, J., and Priess, J.R. 1996. MEX-3 is a $\mathrm{KH}$ domain protein that regulates blastomere identity in early C. elegans embryos. Cell 87: 205-216.

Dsouza, M., Larsen, N., and Overbeek, R. 1997. Searching for patterns in genomic data. Trends Genet. 13: 497-498.

Evans, T.C., Crittenden, S.L., Kodoyianni, V., and Kimble, J. 1994. Translational control of maternal glp-1 mRNA establishes an asymmetry in the C. elegans embryo. Cell 77: 183-194.

Farley, B.M. and Ryder, S.P. 2008. Regulation of maternal mRNAs in early development. Crit. Rev. Biochem. Mol. Biol. 43: 135-162.

Fehon, R.G., Kooh, P.J., Rebay, I., Regan, C.L., Xu, T., Muskavitch, M.A., and Artavanis-Tsakonas, S. 1990. Molecular interactions between the protein products of the neurogenic loci Notch and Delta, two EGF-homologous genes in Drosophila. Cell 61: 523-534.

Gomes, J.E., Encalada, S.E., Swan, K.A., Shelton, C.A., Carter, J.C., and Bowerman, B. 2001. The maternal gene spn-4 encodes a predicted RRM protein required for mitotic spindle orientation and cell fate patterning in early C. elegans embryos. Development 128: 4301-4314.

Hudson, B.P., Martinez-Yamout, M.A., Dyson, H.J., and Wright, P.E. 2004. Recognition of the mRNA AU-rich element by the zinc finger domain of TIS11d. Nat. Struct. Mol. Biol. 11: 257-264.

Hunter, C.P. and Kenyon, C. 1996. Spatial and temporal controls target pal-1 blastomere-specification activity to a single blastomere lineage in C. elegans embryos. Cell 87: 217-226.

Kuersten, S. and Goodwin, E.B. 2003. The power of the 3'-UTR: Translational control and development. Nat. Rev. Genet. 4: 626-637.

Lai, W.S., Carballo, E., Strum, J.R., Kennington, E.A., Phillips, R.S., and Blackshear, P.J. 1999. Evidence that tristetraprolin binds to AU-rich elements and promotes the deadenylation and destabilization of tumor necrosis factor $\alpha$ mRNA. Mol. Cell. Biol. 19: 4311-4323.

Lai, W.S., Carrick, D.M., and Blackshear, P.J. 2005. Influence of nonameric AU-rich tristetraprolin-binding sites on mRNA deadenylation and turnover. J. Biol. Chem. 280: 34365-34377.

Lee, M.H. and Schedl, T. 2001. Identification of in vivo mRNA targets of GLD-1, a maxi-KH motif containing protein required for $C$. elegans germ cell development. Genes \& Dev. 15: 2408-2420.

Maduro, M.F., Meneghini, M.D., Bowerman, B., BroitmanMaduro, G., and Rothman, J.H. 2001. Restriction of mesendoderm to a single blastomere by the combined action of SKN-1 and a GSK- $3 \beta$ homolog is mediated by MED- 1 and -2 in C. elegans. Mol. Cell 7: 475-485.

Marin, V.A. and Evans, T.C. 2003. Translational repression of a $C$. elegans Notch mRNA by the STAR/KH domain protein GLD-1. Development 130: 2623-2632.

Mello, C.C., Draper, B.W., and Priess, J.R. 1994. The maternal genes apx-1 and glp-1 and establishment of dorsal-ventral polarity in the early C. elegans embryo. Cell 77: 95-106.

Mello, C.C., Schubert, C., Draper, B., Zhang, W., Lobel, R., and Priess, J.R. 1996. The PIE-1 protein and germline specification in C. elegans embryos. Nature 382: 710-712.

Ogura, K., Kishimoto, N., Mitani, S., Gengyo-Ando, K., and Kohara, Y. 2003. Translational control of maternal glp-1 mRNA by POS-1 and its interacting protein SPN-4 in Caenorhabditis elegans. Development 130: 2495-2503.

Pagano, J.M., Farley, B.M., McCoig, L.M., and Ryder, S.P. 2007. Molecular basis of RNA recognition by the embryonic polarity determinant MEX-5. J. Biol. Chem. 282: 8883-8894. 
Praitis, V., Casey, E., Collar, D., and Austin, J. 2001. Creation of lowcopy integrated transgenic lines in Caenorhabditis elegans. Genetics 157: $1217-1226$.

Rambo, R.P. and Doudna, J.A. 2004. Assembly of an active group II intron-maturase complex by protein dimerization. Biochemistry 43: 6486-6497.

Reese, K.J., Dunn, M.A., Waddle, J.A., and Seydoux, G. 2000. Asymmetric segregation of PIE- 1 in C. elegans is mediated by two complementary mechanisms that act through separate PIE-1 protein domains. Mol. Cell 6: 445-455.

Rocheleau, C.E., Downs, W.D., Lin, R., Wittmann, C., Bei, Y., Cha, Y.H., Ali, M., Priess, J.R., and Mello, C.C. 1997. Wnt signaling and an APC-related gene specify endoderm in early $C$. elegans embryos. Cell 90: 707-716.

Ryder, S.P., Frater, L.A., Abramovitz, D.L., Goodwin, E.B., and Williamson, J.R. 2004. RNA target specificity of the STAR/GSG domain post-transcriptional regulatory protein GLD-1. Nat. Struct. Mol. Biol. 11: 20-28.

Schubert, C.M., Lin, R., de Vries, C.J., Plasterk, R.H., and Priess, J.R. 2000. MEX-5 and MEX-6 function to establish soma/ germline asymmetry in early C. elegans embryos. Mol. Cell 5: $671-682$.

Seydoux, G. and Dunn, M.A. 1997. Transcriptionally repressed germ cells lack a subpopulation of phosphorylated RNA polymerase II in early embryos of Caenorhabditis elegans and Drosophila melanogaster. Development 124: 2191-2201.

Seydoux, G., Mello, C.C., Pettitt, J., Wood, W.B., Priess, J.R., and Fire, A. 1996. Repression of gene expression in the embryonic germ lineage of C. elegans. Nature 382: 713-716.
Shimada, M., Yokosawa, H., and Kawahara, H. 2006. OMA-1 is a P granules-associated protein that is required for germline specification in Caenorhabditis elegans embryos. Genes Cells 11: 383-396.

Shirayama, M., Soto, M.C., Ishidate, T., Kim, S., Nakamura, K., Bei, Y., van den Heuvel, S., and Mello, C.C. 2006. The conserved kinases CDK-1, GSK-3, KIN-19, and MBK-2 promote OMA-1 destruction to regulate the oocyte-to-embryo transition in $C$. elegans. Curr. Biol. 16: 47-55.

Sonnichsen, B., Koski, L.B., Walsh, A., Marschall, P., Neumann, B., Brehm, M., Alleaume, A.M., Artelt, J., Bettencourt, P., Cassin, E., et al. 2005. Full-genome RNAi profiling of early embryogenesis in Caenorhabditis elegans. Nature 434: 462-469.

Subramaniam, K. and Seydoux, G. 1999. nos-1 and nos-2, two genes related to Drosophila nanos, regulate primordial germ cell development and survival in Caenorhabditis elegans. Development 126: 4861-4871.

Sulston, J.E., Schierenberg, E., White, J.G., and Thomson, J.N. 1983. The embryonic cell lineage of the nematode Caenorhabditis elegans. Dev. Biol. 100: 64-119.

Tabara, H., Hill, R.J., Mello, C.C., Priess, J.R., and Kohara, Y. 1999. pos- 1 encodes a cytoplasmic zinc-finger protein essential for germline specification in C. elegans. Development 126: 1-11.

Thorpe, C.J., Schlesinger, A., Carter, J.C., and Bowerman, B. 1997. Wnt signaling polarizes an early C. elegans blastomere to distinguish endoderm from mesoderm. Cell 90: 695-705.

Worthington, M.T., Pelo, J.W., Sachedina, M.A., Applegate, J.L., Arseneau, K.O., and Pizarro, T.T. 2002. RNA binding properties of the AU-rich element-binding recombinant Nup475/TIS11/ tristetraprolin protein. J. Biol. Chem. 277: 48558-48564. 

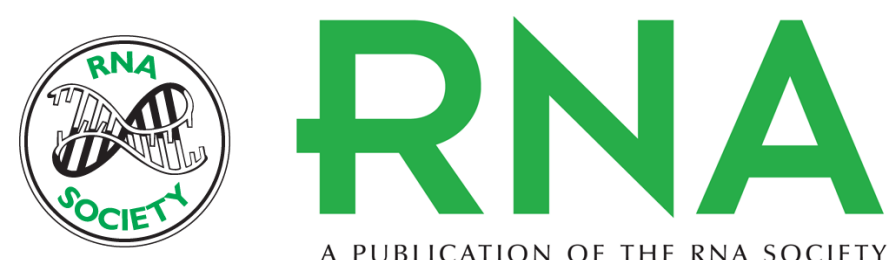

A PUBLICATION OF THE RNA SOCIETY

\section{RNA target specificity of the embryonic cell fate determinant POS-1}

Brian M. Farley, John M. Pagano and Sean P. Ryder

RNA 2008 14: 2685-2697 originally published online October 24, 2008

Access the most recent version at doi:10.1261/rna.1256708

Supplemental

Material

References This article cites 42 articles, 18 of which can be accessed free at:

http://rnajournal.cshlp.org/content/14/12/2685.full.html\#ref-list-1

http://rnajournal.cshlp.org/content/suppl/2008/10/24/rna.1256708.DC1

\section{License}

Email Alerting

Service

Receive free email alerts when new articles cite this article - sign up in the box at the

top right corner of the article or click here.

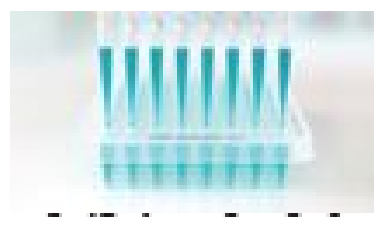

Providing Precise Solutions for your research.

To subscribe to RNA go to:

http://rnajournal.cshlp.org/subscriptions 